\title{
Análise da fermentação alcoólica do kefir em biorreator
}

\author{
Analysis of the alcoholic fermentation of kefir in a bioreactor \\ Renata Ferreira Miranda, Cristiane de Souza Siqueira Pereira, Imar Oliveira de Araújo.
}

Como citar esse artigo. Miranda RF, Pereira CSS, Araújo IO. Análise da fermentação alcoólica do kefir em biorreator. Revista Teccen. 2014 Jan./Dez.; $07 \quad$ (1/2): 21-26.

\begin{abstract}
Resumo
A cana-de-açúcar é a principal matéria-prima utilizada no Brasil para fermentação alcoólica. Neste trabalho, objetivou-se avaliar o efeito do kefir quanto à sua viabilidade para produção de etanol por meio da fermentação alcoólica. Os grãos de kefir se constituem de uma associação simbiótica de leveduras, bactérias ácido-láticas e bactérias ácido-acéticas tradicionalmente utilizadas para a produção de leites fermentados de baixo teor alcoólico, o que gera uma bebida associada à longevidade e considerada terapêutica. A partir de fermentação conduzida em biorreator piloto verificou-se o consumo de açúcar e produção de etanol com os grãos de kefir. O estudo realizado apresentou resultados satisfatórios para fermentação do kefir na produção de etanol. Palavras-Chave: Kefir. Produção de etanol. Biorreator.
\end{abstract}

\begin{abstract}
The cane sugar is the main feedstock used in Brazil for ethanol fermentation. This study aimed to evaluate the effect of kefir and its feasibility for production of ethanol by fermentation. Kefir grains are constituted of a symbiotic association of yeasts, lactic-acid bacteria and acetic acid bacteria. Traditionally it is used to produce fermented milk with low alcohol content, where the drink is associated with longevity is considered therapeutic. Using brown sugar as a substrate and the bioreactor through the trials it was found consumption of sugar and ethanol production with kefir grains, compared to the variables needed for the fermentation was conducted as well. The study showed satisfactory results for kefir fermentation for ethanol production. Keywords: Kefir. Production of ethanol. Bioreactor.
\end{abstract}

\section{Introdução}

Acana-de-açúcaréum dos principais produtos agrícolas do Brasil. É uma matéria-prima abundante e de baixo custo. O caldo de cana-de-açúcar se destina tanto para a produção de açúcar quanto de álcool, produzindo também a cachaça, bebida alcoólica típica brasileira. Segundo o Programa Brasileiro de Desenvolvimento da Aguardente de Cana (PBDAC), a aguardente de canaéa terceira bebida destilada mais consumida no mundo e a primeira no Brasil (Embrapa, 2012).

O principal processo produtivo de aguardente é realizado em batelada e utiliza matérias-primas açucaradas como melaço e caldo de cana, e como agente fermentador a levedura (Saccharomyces cerevisae). Entretanto, outros microrganismos são também capazes de produzir etanol com a utilização de matérias-primas açucaradas como substrato (Dornelles; Rodrigues, 2006).

Segundo Witthuhn et al. (2004) e Marchiori (2007), o kefir é originário das montanhas do Cáucaso. Em eslavo,
Kephir significa "bem-estar". É um leite fermentado, de fácil preparo e economicamente acessível, originado da ação da microbiota natural presente nos grãos ou grumos de kefir (Witthuhn et al., 2004 e Marchiori, 2007).

Diversos autores descrevem o kefir como uma associação simbiótica de leveduras, bactérias ácido-láticas e bactérias ácido-acéticas envoltas por uma matriz de polissacarídeos referidos como kefiran. Apresentam tamanhos entre $0,5-3,5 \mathrm{~cm}$ de diâmetro, volume de $0,5-20,0 \mathrm{~mL} /$ grão, forma irregular, amarelados ou esbranquiçados (Rivière $\mathrm{e}$ Kooiman, 1967; Pintado et al., 1996; Hertzler e Clancy, 2003), apud Moreira (2011), conforme apresentado na Figura 1.

A composição microbiana dos grãos de kefir varia conforme a região de origem, o tempo de utilização, o substrato utilizado para proliferação dos grãos e as técnicas usadas em sua manipulação (Wszolek et al., 2001; Witthuhn et al., 2004), apud Moreira (2011). A Figura 2 mostra a microscopia eletrônica de grãos de kefir e a superfície interior e externa do grão de kefir. 


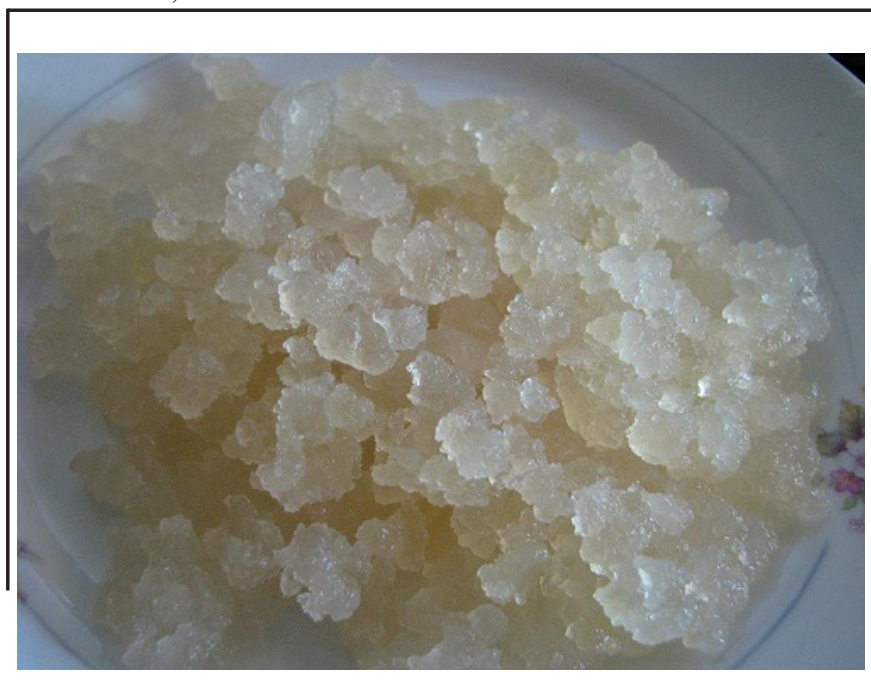

Figura 1. Grãos de kefir.

Fonte: Moreira et al., 2008
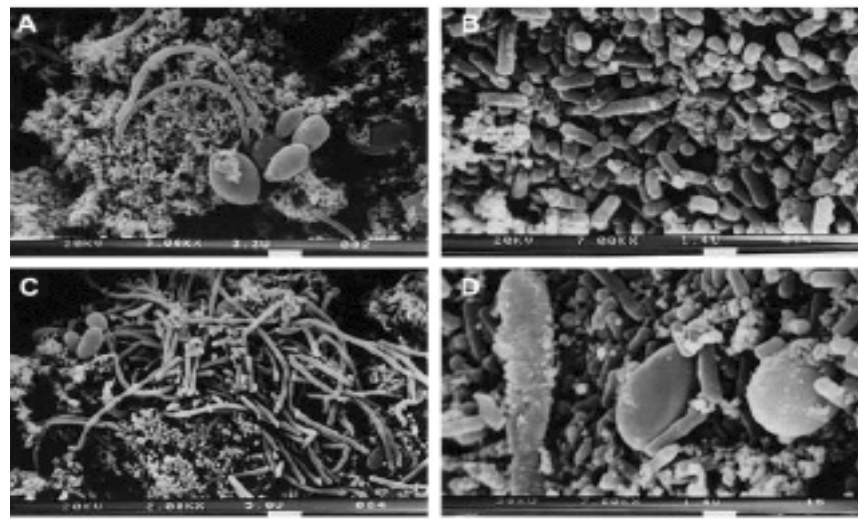

Figura 2. Microscopia eletrônica de grãos de kefir.

(A, C) Superficie interior do grão de kefir. (B, C) Superfície externa do grão de kefir.

Fonte: Zhou et al., 2009

De acordo com Martins (2006), o kefir tem vários conceitos e a FAO/WHO (2001) propôs uma definição de kefir baseada na composição microbiológica do grão de kefir (a cultura-mãe usada para produzir kefir) como o produto final. Esta definição é apresentada na Tabela 1.

OCodex Alimentarius éum código denormas básicas sobre alimentos. As principais finalidades deste código são: proteger a saúde dos consumidores, assegurarem práticas justas no comércio de alimentos e promover a coordenação de todo trabalho sobre normas alimentares realizado por organizações internacionais governamentais e não governamentais. O Brasil também é membro do Codex Alimentarius, tendo criado em 1980, o Comitê do Codex Alimentarius do Brasil (CCAB), mediante as Resoluções 01/8 e 07/88 do Conselho Nacional de Metrologia, Normalização e Qualidade Industrial (Conmetro). O CCAB tem como principais finalidades a participação, em representação do país, nos comitês internacionais do Codex Alimentarius e a defesa dos interesses nacionais, bem como a utilização das Normas Codex como referência para a elaboração e atualização da legislação e regulamentação nacional de alimentos (Martins, 2006).
Tabela 1. Codex Alimentarius do kefir..

\section{Definição}

Cultura-mãe preparada a partir de grãos de kefir, Lactobacillus Kefir e espécies do gênero Leuconostoc, Lactococcus e Acetobacter crescendo em uma relação simbiótica muito forte. Grãos de kefir constituem ambas as leveduras fermentadoras de lactose (kluyveromyces marxianus) e não fermentadoras de lactose (Saccharomyces unisporus, Sacharomyces cerevisae e Sacharomyces exiguus)

\section{Composição}

Proteína do leite (\% w/w) - min. 2,8

Gordura do leite ( $\% \mathrm{~m} / \mathrm{m})-<10$

Acidez titulável, expressada com \% de acido lático $\min 0,6-(\% \mathrm{~m} / \mathrm{m})$

Etanol (\%vol.w) - não detectado

Resumo de microorganismos contituintes da cultura mãe - min. 107 - (cfu/g em total)

Leveduras (cfu/g) - min. 104

Fonte. Codex Standard for Fermented Milks Codex Stan 243-2003.

Segundo os dados de Souza et al (1984) apud (Carvalho, 2009), o kefir possui consistência cremosa e espessa, leve gosto ácido, aroma moderado de levedura fresca, efervescência carbonatada natural e pode conter entre 0,08 e $2 \%$ de álcool. Os principais produtos da fermentação são o ácido láctico, ácido acético, acetaldeído, diacetil, etanol e $\mathrm{CO}_{2}$, de acordo com a Tabela 2.

Tabela 2. Composição físico-química do kefir.

\begin{tabular}{cc}
\hline Componentes & Valores aproximados \\
\hline Água & $87 \%$ \\
\hline Acidez em graus Dornic $\left({ }^{\circ} \mathrm{D}\right)$ & 80 (final do processo) \\
\hline Proteínas totais & $3,4-4,2 \%$ \\
\hline Sacarose & $4,4($ mínimo) \\
\hline Gordura & $0,5-3,0 \%$ \\
\hline Matérias albuminóides & $3,1 \%$ \\
\hline pH & $4,2-4,5$ \\
\hline Acidez volátil & $3,9 \mathrm{~mL}$ de $\mathrm{NaOH} \mathrm{N} / 10 \times 100 \mathrm{~mL}$ \\
\hline Caseína & $2,8 \%$ \\
\hline Albumina & $0,2 \%$ \\
\hline Lactose & $2,6-3,75 \%$ \\
\hline Ácido lático & $0,7 \%$ \\
\hline Álcool (etanol) & $0,23-1,0 \% \mathrm{v} / \mathrm{v} ?$ \\
\hline Gás carbônico & $20-25 \%(\mathrm{v} / \mathrm{v})$ \\
\hline Minerais & $0,74-0,8 \%$ \\
\hline Diacetil & $0,49 \mathrm{mg} / \mathrm{L}$ \\
\hline Acetaldeído & $1,30 \mathrm{mg} / \mathrm{L}$ \\
\hline
\end{tabular}

Fonte. Souza et al (1984) apud (Carvalho, 2009) 
O aroma, sabor e a composição do kefir dependem do tipo de leite, processo de produção, origem dos grãos ou da cultura starter (Irigoyen et al.; 2005; Otles e Cagindi, 2003; Farnworth e Mainville, 2005), apud Montanuci et al. (2010).

A bebida fermentada à base de leite é frequentemente associada à longevidade, e é considerada terapêutica. As atribuições da bebida têm despertado recentemente o interesse de outros mercados e encorajado a pesquisa na área (Dornelles e Rodrigues, 2006).

De acordo com Wróblewska et al. (2009) o kefir possui substâncias bioterapêuticas capazes de estimular células do sistema imunológico e seu consumo melhora a digestão. Segundo Montanuci et al. (2010), devido a vários efeitos positivos no sistema imune, sistema gastrointestinal e metabolismo do colesterol, o kefir tem se tornado popular. Ainda segundo este autor, algumas propriedades antitumorais, antibacterianas e antifúngicas foram demonstradas em pesquisas in vitro e em animais, e são citadas por Ertekin e Guzel-seydim (2010); Farnworth e Mainville (2008) Hertzler e Clancy (2003).

$\mathrm{Na}$ Rússia, onde é produzido e comercializado em larga escala, é o leite fermentado mais popular depois do iogurte. Nos Estados Unidos, o produto é comercializado há mais de 20 anos e pode ou não conter álcool. No Brasil, o kefir é pouco conhecido. Todavia, é obtido em nível caseiro, principalmente por pessoas procedentes de países em que seu uso é tradicional (Garcia et al.,1984) apud Carneiro (2010).

Dornelles e Rodrigues (2006) realizaram fermentação alcoólica de caldo de cana comparando grãos de kefir e fermento de panificação (Saccharomyces cerevisae). Os ensaios foram realizados em erlenmeyers protegidos com tampões de algodão por sete dias. Os autores avaliaram que a fermentação conduzida com grãos de kefir é viável e tem um aroma diferenciado e agradável, aplicável na produção de álcool. Quando comparado com a levedura Saccharomyces cerevisae seu rendimento em etanol produzido é menor.

O objetivo do presente estudo foi avaliar a produção de etanol a partir da fermentação de grãos de kefir, com utilização de açúcar mascavo como substrato. A fermentação foi realizada em um biorreator-piloto.

\section{Metodologia}

A fermentação e as análises foram realizadas no Centro de Tecnologia SENAI-RJ Alimentos e Bebidas, onde os grânulos de kefir foram mantidos em solução de açúcar mascavo, diluído em água a $24^{\circ} \mathrm{C}$. Diariamente, o meio de cultivo era renovado até a fermentação. A Figura 3 apresenta o kefir cultivado em açúcar mascavo.

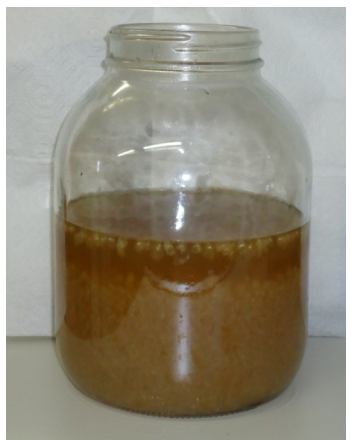

Figura 3. Kefir cultivado em açúcar mascavo. Fonte: Arquivo pessoal

\section{Análise do caldo bruto (solução de açúcar mascavo)}

A solução de açúcar mascavo utilizada para a fermentação foi caracterizada quanto ao: teor de sólidos solúveis $\left({ }^{\circ} \mathrm{Brix}\right) ; \mathrm{pH}$ e teor de açúcares determinados pelo método do DNS (Miller, 1959).

Para determinação dos açúcares foi utilizado um espectrofotômetro Micronal modelo B582. O pH foi determinado por potenciometria direta, com utilização de pHmetro modelo Q400MT. O teor de sólidos solúveis foi determinado por refratometria, com utilização de um refratômetro ABBE digital modelo Q76780. Todas as análises foram feitas em triplicata.

\section{Processo de Fermentação}

Foram realizadas três fermentações variando a massa de kefir. Os grãos de kefir foram utilizados em base úmida, cuja massa é 10 vezes maior que a base seca. A fermentação foi realizada de forma estática no biorreator, a uma temperatura de $25-30^{\circ} \mathrm{C}$. Para a etapa de fermentação foi utilizado o biorreator Tec-Bio modelo 7,5L. A Figura 4 ilustra o biorreator utilizado.

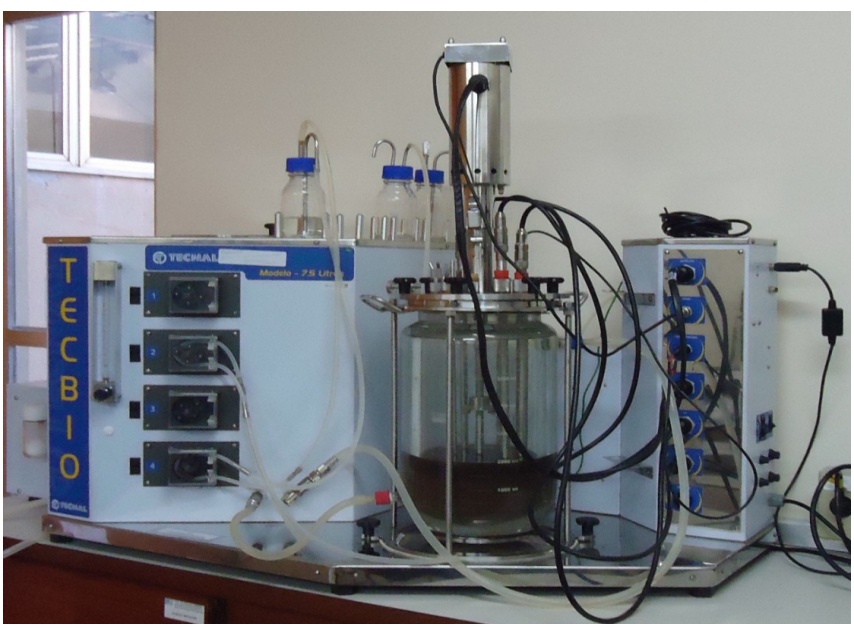

Figura 4. Fermentação do kefir em biorreator. Fonte: Arquivo pessoal 
O primeiro e o terceiro ensaio de fermentação foram realizados sem agitação, porém, uma agitação adequada na fermentação traz inúmeras vantagens ao sistema, como maior eficiência fermentativa, melhor homogeneização do sistema, com produção de uniformidade do meio dispersando e mantendo em suspensão as partículas sólidas, facilitando as reações químicas e bioquímicas. Desse modo, o segundo ensaio de fermentação foi realizado sob agitação de $100 \mathrm{rpm}$.

\section{Análise do caldo fermentado}

O caldo fermentado foi analisado quanto ao teor de açúcar residual, $\mathrm{pH}$ e teor alcoólico. O teor alcoólico foi analisado no equipamento Beer Analyser, fabricado pela empresa Anton Paar.

Quanto ao rendimento do experimento foi relacionado à razão entre o etanol consumido e o açúcar consumido, calculado por meio da seguinte equação,, segundo (Dornelles e Rodrigues, 2006).

Rendimento $(\%)=\frac{\text { Etanolproduzido }(\mathrm{g} / \mathrm{L})}{\text { Zlçucar consumido }(\mathrm{g} / \mathrm{L})} \times 100$

\section{Resultados e Discussão}

A Tabela 3 apresenta as condições iniciais utilizadas na fermentação.

Tabela 3. Condições iniciais da fermentação.

\begin{tabular}{cccc}
\hline Fermentação & $\begin{array}{c}\text { Biomassa em } \\
\text { base úmida } \\
(\mathbf{g} / \mathbf{m L})\end{array}$ & ${ }^{\circ}$ Brix & pH \\
\hline 1 & 300 & 9,8 & 4,91 \\
\hline 2 & 677 & 8,0 & 4,96 \\
\hline 3 & 160 & 9,7 & 4,42 \\
\hline
\end{tabular}

Fonte. Arquivo pessoal

Decorridos os sete dias de fermentação, as células foram removidas com uma peneira de aço inox. O caldo fermentado foi avaliado mediante determinação de açúcar residual e teor de etanol. Na Tabela 4 são apresentados os valores obtidos na fermentação alcoólica.

Tabela 4. Resultados obtidos na fermentação com o kefir.

\begin{tabular}{cccccc}
\hline Fermentação & ${ }^{\circ}$ Brix & $\begin{array}{c}\text { A ç ú c a r } \\
\text { residual } \\
(\mathbf{g} / \mathbf{L})\end{array}$ & pH & $\begin{array}{c}\text { Rendimento } \\
(\%)\end{array}$ & Etanol (g/L) \\
\hline 1 & 4,1 & $1,04 \pm 0,001$ & 2,82 & 19,67 & $20,46 \pm 0,005$ \\
\hline 2 & 2,6 & $1,40 \pm 0,02$ & 3,92 & 14,32 & $20,06 \pm 0,04$ \\
\hline 3 & 4,6 & $1,30 \pm 0,01$ & 3,68 & 11,94 & $15,53 \pm 0,04$ \\
\hline
\end{tabular}

Fonte. Arquivo pessoal

Os valores de ${ }^{\circ}$ Brix e $\mathrm{pH}$ foram determinados no início e ao final do processo de fermentação, e são apresentados nas Figura 5 e 6, respectivamente.

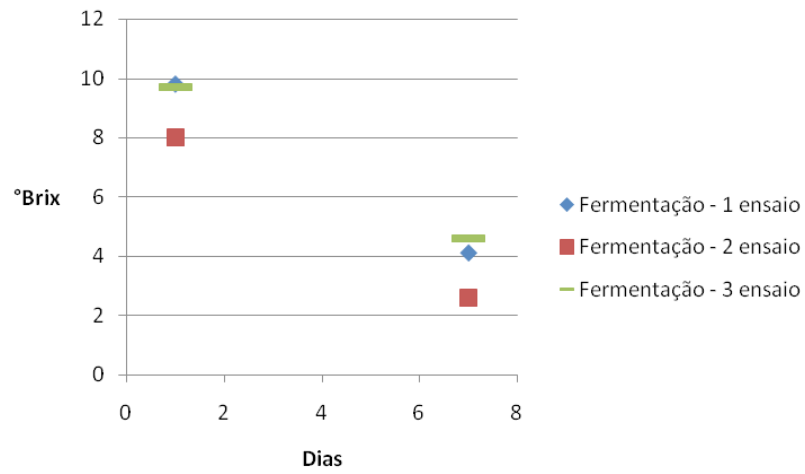

Figura 5. ${ }^{\circ}$ Brix obtido após fermentação. Fonte: Arquivo pessoal
Pode-se observar que o ${ }^{\circ}$ Brix da primeira e terceira fermentação são maiores, quando comparado com a segunda. Essa diferença pode ser decorrida do processo de agitação ocorrido na segunda fermentação, o que facilita o consumo do açúcar pelo kefir.

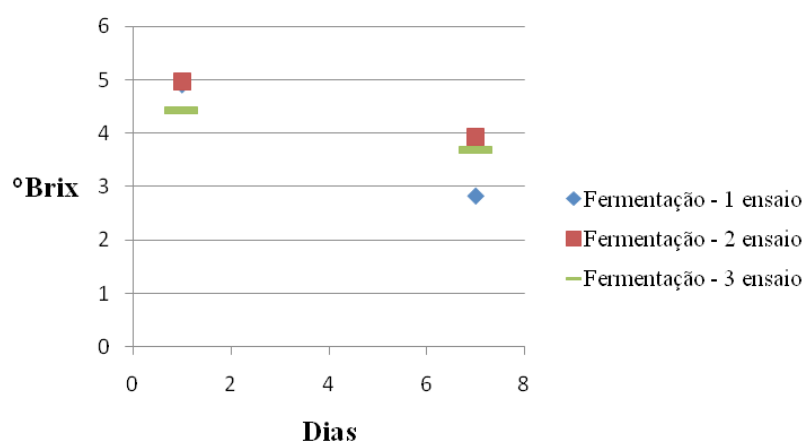

Figura 6. Comportamento do $\mathrm{pH}$ durante a fermentação do kefir. Fonte: Arquivo pessoal 
Com relação aos valores de $\mathrm{pH}$, a primeira fermentação apresentou valores de $\mathrm{pH}$ menor que a segunda e terceira. Segundo Dornelles e Rodrigues (2006) os baixos valores de $\mathrm{pH}$ estão relacionados à produção de ácidos orgânicos durante a fermentação.

Segundo Aquarone et al. (2001), fermentações conduzidas em meios ácidos resultam em maiores rendimentos em etanol, pelo fato de restringir o crescimento do fermento, com a conseqüente redução da produção de glicerol, ao mesmo tempo em que reduz a contaminação bacteriana em leveduras industriais.

Os rendimentos na produção de etanol do presente trabalho foram de 20,46 $\pm 0,005$ para primeira fermentação e $20,06 \pm 0,04$ para segunda, valores estes na faixa do rendimento esperado, diferenciando somente a terceira fermentação em que se obteve $15,53 \pm 0,04$ de etanol, quando comparado com as demais fermentações. Este fato pode estar ligado à quantidade de biomassa utilizada, e que foi menor, comparada às três fermentações.

Dornelles e Rodrigues (2006) apresentaram rendimento máximo em etanol de $37,59 \%$ e valor mínimo de 20,80\% após fermentação com kefir, quando comparado ao caldo fermentado com a levedura Saccharomyces cerevisae.

O processo de agitação não exerceu influência significativa na segundafermentação quando comparado com a primeira e a terceira fermentação. Ambas foram conduzidas sem agitação. O rendimento de etanol produzido para ambos os processos de fermentação obteve rendimentos próximos.

De acordo com Dornelles e Rodrigues (2006), quanto maior a quantidade de açúcar inicial, maior é a quantidade de etanol produzido. Porém, este comportamento não foi observado no presente estudo, visto que a quantidade de substrato inicial não exerceu influência significativa no teor de etanol produzido, quando comparamos as fermentações realizadas. O substrato (açúcar mascavo) utilizado no experimento contém menos impurezas em relação aos outros, e proporciona mais nutrientes ao meio, o que é de muita importância para a fermentação.

Garrote el al. (1998), apud Carneiro (2010), sugeriram que a concentração de $10 \mathrm{~g} / \mathrm{L}$ de grãos de kefir é adequada para produzir um produto viscoso (leite) e não muito ácido. Já a concentração de $100 \mathrm{~g} / \mathrm{L}$ foi recomendada para uma bebida ácida, com baixa viscosidade e mais efervescente. Para Sarkar (2008), a proporção de 5\% provou ser adequada para produção de etanol e ácidos voláteis. Carneiro (2010) cita que as quantidades de etanol produzidas durante a fermentação do kefir dependem das condições utilizadas no processo.

\section{Conclusão}

Os resultados apresentados acima permitem concluir que a fermentação do kefir apresenta-se como uma possibilidade para as indústrias.

$\mathrm{O}$ estudo realizado apresentou resultados satisfatórios para a fermentação do kefir, com vistas à produção de etanol, os quais podem ser tomados como base para trabalhos futuros que busquem realizar ajuste para um melhor rendimento do processo ou para verificar o comportamento de outras variáveis para melhor atuação do kefir.

\section{Referências}

Agencia de Informação Emprapa. Endereço: http://www.agencia.cnptia.embrapa. br/gestor/cana-de-acucar/arvore/CONT000fiog1ob502wyiv80z4s473agi63ul. html. Acesso em: 15 de janeiro de 2012.

Aquarone, E.; Borzani, W.; Schmidell, W.; Lima, U. L. Biotecnologia Industrial, São Paulo, Edgard Blücher, 2001. v. 3, 520p.

Carneiro, R. P., (2010). Desenvolvimento de uma cultura iniciadora para produção de kefir. Tese apresentada a título de Mestre em Ciência de Alimentos pelo Programa de Pós-Graduação em Ciência de Alimentos da Faculdade de Farmácia da Universidade Federal de Minas Gerais.

Carvalho, C.; Silva, M.; Cardoso, P. Caracterização de produto, Leite fermentado com Kefir. FCUP - Novembro 2009. Disponível em: http://aefcup.pt/ apontamentos/CE-Qualidade-SegurancaAlimentar/claudiocarvalho. Acessado em: 22 de abril de 2012.

Dornelles, A. S.; Rodrigues, S. (2006). Fermentação Alcoólica de Caldo de Cana utilizando grãos de Kefir. Ciência Agronômica, v. 37, n. ${ }^{\circ}$ 3, pp. 386-390.

Dornelles, A. S.; Rodrigues, S.; Garruti, D. S. Aceitação e perfil sensorial das cachaças produzidas com kefir e saccharomyces cerevisae. Ciência e Tecnologia de Alimentos, ISSN 0101-2061, pp. 518-522, 2009.

Ertekin, B.; Guzel-Seydim, Z. (2010). Effect of fat replaces on kefir quality. Journal of Science Food Agriculture, London, v. 90, n. ${ }^{\circ}$ 4, pp. 1-6.

FAO/WHO (2001). CODEX Standard for Fermented Milks \#243. Disponível em: http://www.codexalimentarius.net/web/standard_list.jsp

Farnworth, E. D.; Mainville, A. (2008). Kefir-A Fermented Milk Product: Handbook of fermented functional foods functional foods and nutraceuticals series. 2. ed. New York: CRC Press, n. ${ }^{\circ}$ 4, pp. 89-128

Garcia, S.; Souza, G.; Valle, J.L. E. (1984). Quefir e sua tecnologia - aspectos gerais. Boletim do Instituto de Tecnologia de Alimentos, v. 21, n. ${ }^{\circ}$ 2, pp. $137-$ 155 .

Garrote, G. L.; Abraham, A. G.; De Antoni, G. L.(1998) Characteristics of kefir prepared with different grain: milk ratios. Journal of Dairy Research, v. 65, pp. 149-154.

Hertzler, S.R.; Clancy, S.M. (2003). Kefir improves lactose digestion and tolerance in adults with lactose maldigestion. J. Am. Diet. Assoc., v.153, pp.582587.

Irigoyen, A.; Arana, I.; Castiella, M.; Torre, P.; Ibánez, F. C. (2005). Microbiological, physicochemical, and sensory characteristics of kefir during storage. Food Chemistry, London, v. 90, n. ${ }^{\circ}$ 4, pp. 613-620.

Marchiori, R. C. (2007). Caracterização do kefir e propriedades probióticas uma revisão. Revista do Instituto de Laticínios Cândido Tostes. V. 62, p. 21-31, set/out.

Martins, L. S. P.; (2006). Monitoramento da produção de ácidos orgânicos em amostras de leite fermentados pelos grãos kefir e do Tibet utilizando técnicas voltamétricas, RP-HLPC. Tese (Doutorado) - Instituto de Química de São Carlos/Universidade de São Paulo, IQSC, 151p.

Miller, G. L. Use of Dinitrosalicilic Acid Reagent for determination of Reducing Sugar. Analytical Chemistry, v.31, p.426-429, 1959.

Montanuci, F. D.; (2010). Caracterização sensorial e aceitação de Kefir adoçado integral e desnatado com inulina. Braz. J. Food Technol. 6. ${ }^{\circ}$

SENSIBER, 19-21 de agosto de 2010, pp. 79-90 
Moreira, M.E.C., Santos, M.H., Pereira, I.O., Ferraz, V., Barbosa, L.C.A., Schneedorf, J.M. (2008). Atividade antiinflamatória de carboidrato produzido por fermentação aquosa de grãos de quefir. Química Nova 31: 1738-1742.

Moreira, T. R. (2011). Avaliação da eficiência do inóculo kefir na redução de carga orgânica de um efluente de matadouro. Monografia apresentada ao curso de Química Industrial, Universidade Severino Sombra.

Pintado, M.E.; Silva, J.A.L.; Fernandes, P.B. (1996). Microbiological and rheological studies on Portuguese kefir grains. Int. J. Food Sci. Tech., v.31, pp. $15-26$.

Rivière, J.W.M.; Kooiman, P. (1967). Kefiran, a novel polissaccharide produced in kefir grain by Lactobacillus brevis. Arch. Mikrobiol., v. 59, pp.269-278.

Weschenfelder, G.M. Pereira, H.H.C. Carvalho, J.M. Wiest Caracterização físico-química e sensorial de kefir tradicional e derivados. Arq. Bras. Med. Vet. Zootec., v. 63, n.2, pp.473-480, 2011

Witthuhn, R.C.; Schoeman, T.; Cilliers, A. (2004). Impact of preservation and different packaging conditions on the microbial community and activity of kefir grains. Food Microbiol. v. 22, pp.337-344.

Wszolek, M.; Tamime, A.Y.; Muir, D.D. (2001). Properties of kefir made in Scotland and Poland using bovine, Caprine and ovine milk with different starter cultures. Lebensm. Wiss. u. Technol., v. 34, pp.251-261, 2001.

Zhou, J., Liu, X.; Jiang H., Dong M. (2009). Analysis of the microflora in Tibetan kefir grains using denaturing gradient gel electrophoresis. Food Microbiology, v. 26, pp.770-775.

\section{Agradecimentos}

Os autores agradecem ao Centro de Tecnologia de Alimentos e Bebidas SENAI/Vassouras-RJ, ao grupo de pesquisa com kefir da USS, a todos que colaboraram para a pesquisa, em especial, à Nina Ricciardone. 